\begin{tabular}{|c|c|c|}
\hline Beitr. Ent. & Keltern & ISSN 0005-805X \\
\hline $\mathbf{5 9}(2009) 2$ & S. $513-526$ & 15.12 .2009 \\
\hline
\end{tabular}

\title{
Ansifera, a new genus of Campylomyzini with remarkable antennal sensilla
}

\section{(Diptera: Cecidomyiidae: Lestremiinae)}

With 5 figures

Mathias JasChHOF

Summary

The genus Ansifera gen. n. is established for one species, A. japonica sp. n., from Japan and four species, A. asetosa sp. n., A. gombakensis sp. n., A. longipalpus sp. n. and A. malayensis sp. n., from West Malaysia. Adult morphological characters indicate Ansifera belongs to the Campylomyzini and is allied to Neurolyga. The presence of looped translucent sensilla on the male and female antennae is considered an underlying synapomorphy of Ansifera. The looped sensilla of the female are complex circumfila, which are typical of Porricondylinae and Cecidomyiinae, yet the two morphotypes are only superficially similar and certainly result from a parallel development.

\section{Zusammenfassung}

Die Gattung Ansifera gen. n. wird für eine Art (A. japonica sp. n.) aus Japan und vier Arten (A. asetosa sp. n., A. gombakensis sp. n., A. longipalpus sp. n. und A. malayensis sp. n.) aus West-Malaysia begründet. Imaginal-morphologische Befunde sprechen für die Zugehörigkeit von Ansifera zu den Campylomyzini und ihre nähere Verwandtschaft mit Neurolyga. Schlaufenförmige transparente Sensillen auf den Antennen von Männchen und Weibchen werden als underlying synapomorphy von Ansifera bewertet. Die schlaufenförmigen Sensillen des Weibchens sind komplexe Circumfila, die für Porricondylinae und Cecidomyiinae charakteristisch sind, doch beruhen die beiden Morphotypen mit Sicherheit auf Parallelentwicklung.

\section{Key words}

Diptera, Cecidomyiidae, Lestremiinae, Palaearctic region, Oriental region, Japan, Malaysia, new genus, new species, antennal sensilla.

\section{Introduction}

The antennal sensilla of adult gall midges (Cecidomyiidae) are more diverse than those of any other dipteran family. Thin-walled, translucent sensilla in particular occur in a wide variety of different morphotypes. The most elaborate type, circumfila, are restricted to Porricondylinae and Cecidomyiinae (GAGNÉ 1981: Figs 56-64), while the more primitive cecidomyiids, classified in the subfamily Lestremiinae, have various other, simpler types (JASCHHOF \& JAsCHHOF 2009: Fig. 11). The structure of circumfila and other translucent sensilla in Cecidomyiinae suggests they are olfactory receptors with differing roles in males and females (SLIFER \& SEKHON 1971, Solinas \& Nuzzaci 1987, Crook \& Mordue 1999, Zhang \& Yang 2008). The structure of Lestremiinae antennal sensilla has not yet been studied in similar detail, but there is no reason to 
doubt that their translucent sensilla are also chemoreceptors. Form, number and position of translucent sensilla usually differ in the two sexes of one and the same species as well as between different species, a fact that is used in identification and classification. It is worth noting that various morphotypes may occur within one and the same monophyletic group, even small genera. One such genus is Ansifera, a new genus of campylomyzine Lestremiinae that is here erected for five new species from Japan and Malaysia. Ansifera, the "loop-bearers", are peculiar for their looped antennal sensilla. Those of the female are especially elaborate and no less complex than circumfila, but the two morphotypes certainly result from a parallel development. In this paper the looped sensilla, which are a novel morphotype and not found in other Lestremiinae, are documented and the new taxa are described.

\section{Material and methods}

Most specimens were collected during an entomological expedition of the Swedish Museum of Natural History, Stockholm (NHRS), to the Malay Peninsula in 1997. A few other specimens result from the collectings, mainly by the author, for a survey of Lestremiinae diversity in Japan during the years 1998-2000 (cf. JASCHHOF 2000). Holotypes of the new species are deposited either with the Jaschiof collection in the Senckenberg Deutsches Entomologisches Institut, Müncheberg, Germany (SDEI) or in the NHRS. Paratypes and other vouchers are shared between SDEI and NHRS. Specimens were mounted on microscope slides following the procedure of JASCHHOF \& JASCHHOF (2009), which is also the reference for the morphological terminology used here. The name Lestremiinae is used in the traditional sense, denoting a subfamily of the Cecidomyiidae, besides Catotrichinae, Porricondylinae and Cecidomyiinae.

\section{Ansifera gen. n.}

Type species: Ansifera japonica sp. n., by present designation.

\section{Diagnosis:}

Adults only. The translucent antennal sensilla in both sexes are typically looped, which is unknown in any other Campylomyzini and Lestremiinae, and are especially large and elaborate in the female (Fig. 1D-E). Some males have simply hair-shaped sensilla (Fig. 3D), like those in Neurolyga, or small, leaf-shaped sensilla (Fig. 4A), which are unknown from other Campylomyzini but found in many other Micromyidi. There is the propensity toward morphological regression throughout the genus. The combination of regressive characters, such as 3-segmented maxillary palpi, sparse setae on thorax and wings, short apicR1, and indistinct or missing costal break, is not met in any other Campylomyzini with fully developed wings. Male terminalia resemble those in some Neurolyga species (Figs 1C, 2D).

\section{Description:}

Small-sized, males maximally $1.5 \mathrm{~mm}$ long. Head capsule almost globular (Fig. 2A). Postocular bristles sparse or absent. Eye bridge usually slightly shorter laterally than dorsally, lateral ommatidia present. Male antenna with 12 flagellomeres, flagellomere nodes barrel-shaped, with crenulate whorls of sensory hairs, translucent sensilla on proximal 4-5 flagellomeres typically looped (Fig. 1D), otherwise simply hair-shaped (Fig. 3D) or leaf-shaped (Fig. 4A), lengths of flagellomere necks variable among species. Female antenna with 8 flagellomeres, apical flagellomeres 
constricted; flagellomere nodes barrel-shaped, entirely encircled by translucent sensilla, the latter filiform, forming an irregular network that arises from numerous pores and bears several long, one- or two-pointed processes; flagellomere necks long (Fig. 1E). Maxillary palpus 3-segmented, basal segment usually slightly swollen, with numerous hair-shaped translucent sensilla dorsomesally, apical segment longest of all, often asetose (Fig. 1A). Thorax small relative to head (Fig. 2A). Antepronotal lobe asetose. Scutum with sparse lateral and dorsocentral setae. Postphragma large. Wings (Fig. 1B) with regressive features, such as costal break indistinct or missing, apicR1 shorter than 3 times the length of Rs, M obsolete apically, $\mathrm{CuA} 2$ often very short, dorsal setae on veins sparse, ventral setae absent, alar setae comparatively sparse or absent. Dorsal setae on R1, R5, r$\mathrm{m}$ and $\mathrm{CuA}$-stem, or variously reduced. Pattern of sensory buds: apicR1, 2-3; Rs, 1; R5, 1 basal (often situated on same level with Rs), 1-2 mesal/distal; buds often barely discernible due to small size. Scales on tibiae and tarsi sparse or absent. T5 very densely pubescent. Pretarsal claws crescentshaped, with fine teeth. Empodia narrow, slightly shorter than claws. Preabdomen weakly sclerotized, segment 1 asetose, anterior terga with lateral setae, posterior terga with lateral and dorsal setae and sclerotized anterior margins, sterna and pleural membranes 2-8 setose. Tergal plaques $0 / 2 / 2 / 2 / 1 / 1 / 1 / 0$. Male terminalia (Figs $1 C, 2 \mathrm{D}$ ) small; tg9 subtrapezoid, only partly sclerotized, with membranous basal margin; gonocoxites short and wide, with ventral emargination of variable outline, dorsal transverse bridge often projecting beyond ventrobasal margin; antGA missing; gonostyli subcylindrical or tapered toward apex, often slightly flattened, without apical spine; ejaculatory apodeme usually longer than tegmen, with apical extension; tegmen membranous, subtriangular to subrectangular; apices of ejaculatory apodeme and tegmen usually closely linked with one another; ducts of accessory glands not discernible; st 10 not traceable; cerci densely pubescent, asetose. Spermathecae 2, equal in size, comparatively small, strongly sclerotized, globular, with tiny plaques. Ovipositor short, unmodified, basi- and disticercus subequal in length.

Etymology: The name is Latin, meaning loop-bearer, which refers to the peculiar shape of the antennal sensilla. Gender is feminine.

\section{Classification and phylogeny:}

The absence of a sensory bud on $\mathrm{r}-\mathrm{m}$ and the structure of the male terminalia, with simple, spineless gonostyli and long, apically enlarged ejaculatory apodeme, are the main arguments to classify Ansifera with the Campylomyzini (cf. Jaschноғ \& JAsChноғ 2009). Male genitalic characters suggest a closer affinity of Ansifera to the genus Neurolyga Rondani, 1840. The looped antennal sensilla, present in three of the five species, are unique and considered an underlying synapomorphy of Ansifera. A whole set of characters reflect the trends toward miniaturization and morphological regression, which are observable in all but one of the species included. The same phenomena are known from two other Campylomyzini, Micropteromyia ghilarovi MamaEv, 1960 and Neurolyga degenerans (Mamaev \& Mohrig, 1975), which however lack looped sensilla and differ in several other character states (cf. Jaschноғ 1998). The genus Ansifera includes five species, all new to science: $A$. japonica, $A$. malayensis, $A$. gombakensis, $A$. asetosa, and $A$. longipalpus. Apparently there is a complex of sibling species around $A$. longipalpus, which needs further study (see below).

\section{Distribution and phenology:}

To my present knowledge, the distributional range of Ansifera comprises Japan, the Malay Peninsula and Borneo. Most specimens by far, and four of the five species known, were found in the Malay Peninsula. Considering the lack of data on the occurrence of Lestremiinae in most of the region in question, one may assume the centre of the recent distribution of Ansifera lies in the Malay Subregion of the Oriental Region. Ansiferas are forest-dwellers, which cope with environ- 
ments as different as cool-temperate deciduous forest and both mountain and lowland tropical rainforest. On several occasions adult Ansifera were observed flying over moist, strongly rotten wood, which presumably is the substrate where larvae live. The east Palaearctic/Malay distribution pattern, as exhibited by Ansifera, is shared by other lestremiine species groups and genera, such as Pseudoperomyia Jaschiof \& Hippa, 1999.

\section{Species identification:}

Characters to discriminate among Ansifera males lie mainly in the structure of the antennae, maxillary palpi, wings and terminalia. Genitalic characters include the outline of gonocoxites, gonostyli and tegmen, which are structures that may be easily distorted in specimens mounted on slides. Ansifera longipalpus appears to be the most common member of a species complex and further study is needed to assess the extent of individual variation in $A$. longipalpus and to determine the discriminatory characters that separate possible sibling species (see below). As only one Ansifera female is known so far, the possibility to identify species using female characters remains unexplored for the time being. One may anticipate the discovery of many more species of Ansifera, which should be borne in mind when using the key given below.

\section{Key to species (males)}

1 Antennal translucent sensilla always hair-shaped (Fig. 3D) gombakensis sp. $\mathrm{n}$. Antennal translucent sensilla at least partly looped (Figs 1D, 5D) or leaf-shaped (Fig. 4A) 2

2 Postfrons setose. Postocular bristles 5-7. Apical segment of maxillary palpus 3 times as long as the preceding segment or longer (Fig. 5C) longipalpus sp. n.

- Postfrons asetose or with maximally 1 seta. No more than 2 postocular bristles. Apical segment of maxillary palpus 2 times as long as the preceding segment or shorter ........ 3

3 Antennal translucent sensilla leaf-shaped (Fig. 4A). Wing membrane asetose

asetosa sp. n.

- $\quad$ Antennal translucent sensilla looped. Wing membrane setose ..................................... 4

4 Neck of fourth antennal flagellomere much longer than node (Fig. 1D). Ejaculatory apodeme thin, without sclerotized apical extension (Fig. 1C) ....................... japonica sp. n. Neck of fourth antennal flagellomere slightly longer than node (Fig. 2C). Ejaculatory apodeme thicker, with sclerotized, funnel-shaped apical extension (Fig. 2D)

malayensis sp. $\mathrm{n}$.

\section{Ansifera japonica sp. n.}

(Fig. 1A-E)

\section{Diagnosis:}

Males are characterized by the very long flagellomere necks (Fig. 1D), the thin ejaculatory apodeme that lacks a sclerotized apical extension (Fig. 1C), and the acuminate tegmen (Fig. 1C). The female, which is the only known example of a female Ansifera, has complex antennal sensilla of an unmistakable outline (Fig. 1E). 


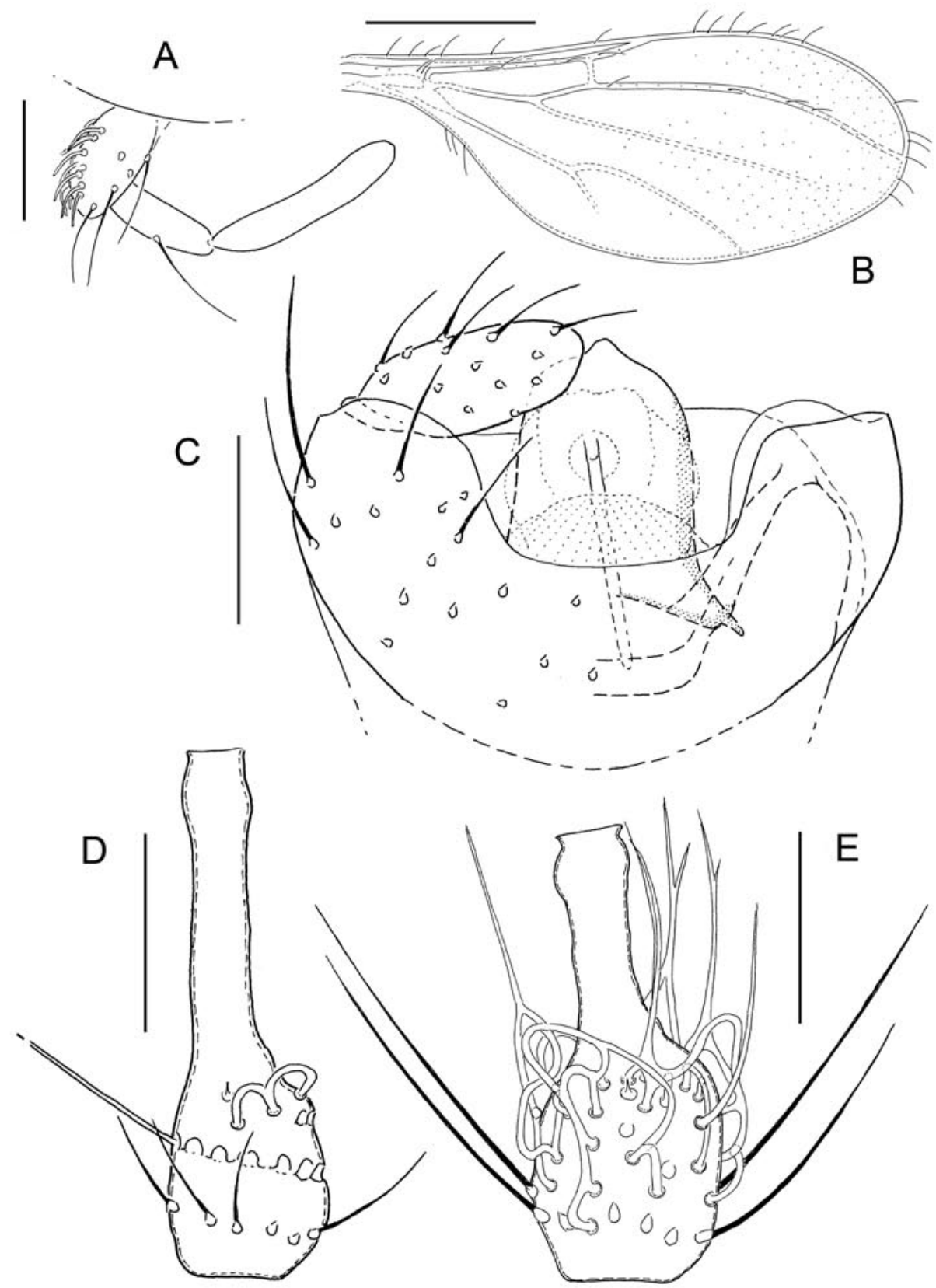

Fig. 1: Ansifera japonica sp. n. - A: male maxillary palpus, lateral view; - B: male wing, dorsal view - C: male terminalia, ventral view; - D: male fourth antennal flagellomere, lateral view; - E: female fourth antennal flagellomere, lateral view. Length of scale bar $=0.05 \mathrm{~mm}$ (for A, C-E) and $0.5 \mathrm{~mm}$ (for B). 


\section{Description:}

Male. Body length: $1.3 \mathrm{~mm}$. Head: Postfrons asetose. Eye bridge 3-4 ommatidia long, shorter laterally than dorsally. Postocular bristles 1-2. Neck of fourth antennal flagellomere much longer than node; node with 1 complete and 1 incomplete crenulate whorl; translucent sensilla looped (Fig. 1D). Maxillary palpus long, basal segment slightly swollen, second segment attached subapically on first, apical segment asetose, clearly longer than preceding segment (Fig. 1A).

Wing: Fig. 1B. Costal break missing. ApicR1 2.5 times the length of Rs. CuA2 very short. Alar setae absent in basal radial cell and in basal medial, anterior cubital and anal areas.

Preabdomen: Terga 2-5 with single lateral setae, terga 6-8 with few lateral and dorsal setae. Terminalia: Fig. 1C. Ventral emargination of gonocoxites broadly U-shaped, dorsal transverse bridge not projecting beyond ventrobasal margin, the latter not reinforced. Gonostylus subcylindrical, slightly flattened, outer surface setose, inner surface with large microtrichia. Ejaculatory apodeme thin, shorter than tegmen, apical extension weakly membranous. Tegmen slightly tapered toward apex, acuminate apically, covered ventrally by membranous pubescent lobe.

Female. Body length: $1.5 \mathrm{~mm}$. Head: Fourth flagellomere Fig. 1E. Other characters as mentioned in the genus description or identical to those in the male.

Immature stages. Unknown.

\section{Distribution and phenology:}

Two specimens, apparently a pair, were Malaise trapped in a deciduous forest on Hokkaido, Japan. No further specimens, either of this or any other Ansifera species, were found in the 340 insect samples studied from all over Japan (cf. JaSCHнOF 2000).

Etymology: The name is derived from Japan, where japonica is the only Ansifera species known.

Types: Holotype: Male, Japan, Hokkaido, Sapporo City, Toyohira, in secondary mixed deciduous forest, 29 June-26 July 1999, by Malaise trap, K. Fukuyama \& M. \& C. JaschHof (in SDEI). Paratype: Female, same data as the holotype (in SDEI).

\section{Ansifera malayensis sp. $\mathbf{n}$.}

(Fig. 2A-D)

\section{Diagnosis:}

Males are characterized by the following features in combination: the antennal translucent sensilla are looped (Fig. 2C), the eye bridge is throughout of equal length (Fig. 2A), the ventral emargination of the gonocoxites is shallow (Fig. 2D), and the gonostyli are comparatively slender (Fig. 2D).

\section{Description:}

Male. Body length: 1.0-1.1 mm. Head: Fig. 2A. Postfrons usually asetose, exceptionally with 1 seta. Eye bridge 4 ommatidia long. Postocular bristles 1-2. Neck and node of fourth antennal flagellomere subequal in length; node with 1 complete and 2 incomplete crenulate whorls, 12 looped translucent sensilla (Fig. 2C). Maxillary palpus comparatively long, first segment not swollen, apical segment longest of all, sparsely setose or asetose (Fig. 2B).

Wing: Costal break indistinct or missing. ApicR1 1.5-2.5 times the length of Rs.

Preabdomen: Segment 2 with no tergal and few sternal setae. Terga 3-4 only with lateral setae, terga 5-8 with lateral and dorsal setae. Terminalia: Fig. 2D. Setae on tg9 sparse. Ventral emargina- 
tion of gonocoxites shallow, dorsal transverse bridge projecting beyond ventrobasal margin, the latter reinforced. Gonostylus subcylindrical, comparatively slender. Ejaculatory apodeme longer than tegmen, apical extension large, funnel-shaped. Tegmen slightly tapered toward apex, the latter membranous, blunt. Cerci projecting far beyond $\mathrm{tg} 9$.

Female and immature stages. Unknown.

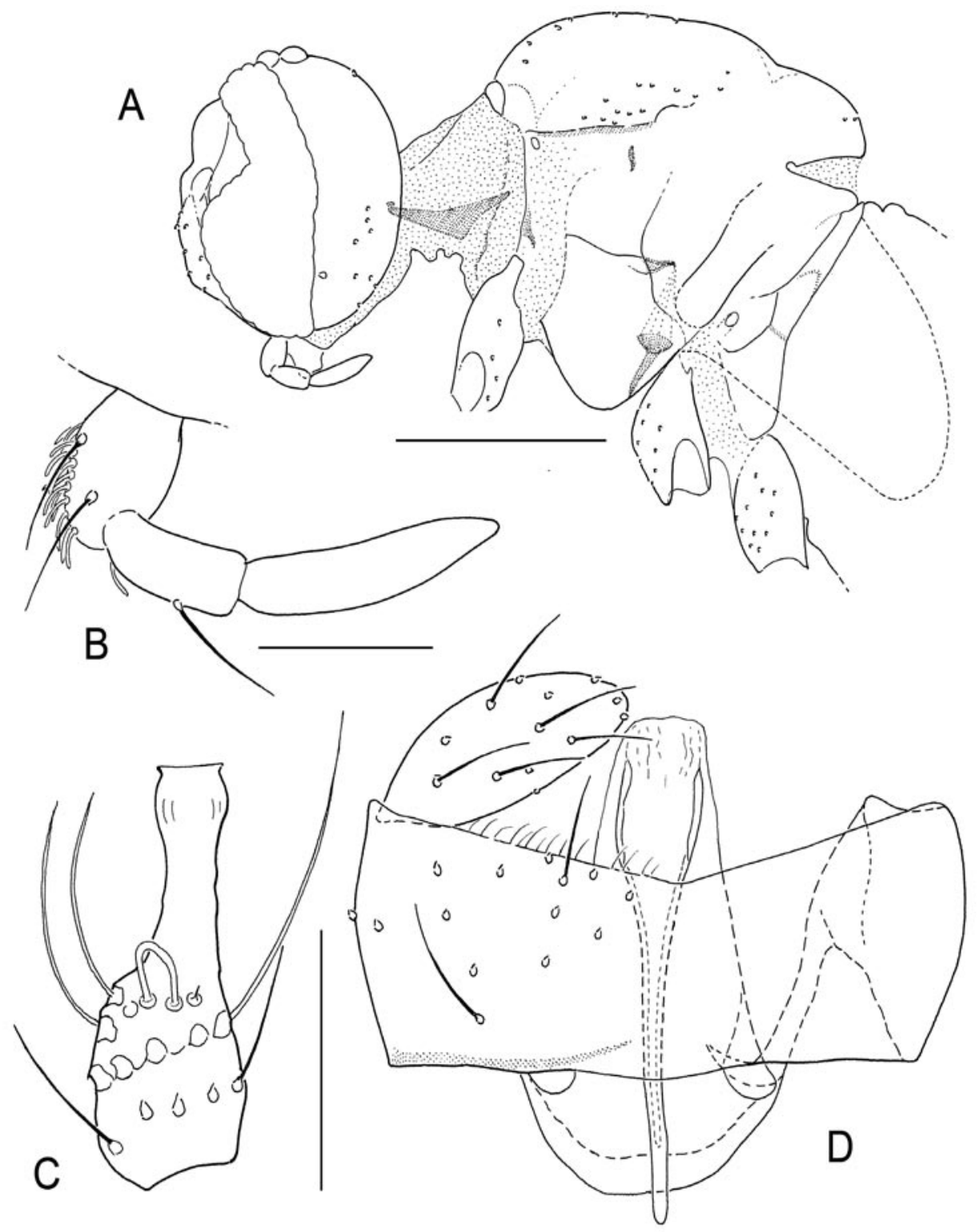

Fig. 2: Ansifera malayensis sp. n., male. - A: head and thorax, lateral view; - B: maxillary palpus, lateral view; - C: fourth antennal flagellomere, lateral view; - D: terminalia, ventral view. Length of scale bar $=0.05 \mathrm{~mm}$ (for B-D) and $0.1 \mathrm{~mm}$ (for A). 


\section{Distribution and phenology:}

Specimens come from two primary rainforests in the Selangor and Pahang Provinces, West Malaysia. The collecting sites are located at altitudes of 250 and $1000 \mathrm{~m}$ above sea level. Specimens were collected over rotten wood or elsewhere in the forest interior and along forest edges.

Etymology: The name refers to Malaysia, where all the known specimens were collected.

Types: Holotype: Male, West Malaysia, Selangor, Ulu Gombak, near University of Malaya Field Studies Centre, in evergreen rainforest, 250 m, 24 Feb.-14 March 1997, by Malaise trap, H. Hippa, M. Jaschhof \& B. Viklund (in NHRS). Paratypes: 2 males, same data as the holotype but 8-21 March 1997; 2 males, same locality, 24 Feb. and 1 March 1997, by sweepnet and aspirator, M. Jaschinof; 1 male, West Malaysia, Pahang, Genting Highlands, Awana, in primary evergreen rainforest, $1000 \mathrm{~m}$, by sweepnet, M. JAschHOF (in NHRS and SDEI).

\section{Ansifera gombakensis sp. n.}

(Fig. 3A-D)

\section{Diagnosis:}

Males are characterized by the combination of the following character states: the antennal translucent sensilla are simply hair-shaped (Fig. 3D), the flagellomere necks are very short (Fig. 3D), the basal palpus segment is clearly swollen (Fig. 3C), the gonostyli are comparatively short (Fig. 3A), and the large ejaculatory apodeme has a sclerotized, funnel-shaped apical extension (Fig. 3A).

\section{Description:}

Male. Body length: 1.0-1.1 mm. Head: Postfrons asetose. Eye bridge 3-5 ommatidia long, shorter laterally than dorsally. Postocular bristles 5 or fewer. Neck of fourth antennal flagellomere shorter than node; node with 1 complete and 2 incomplete crenulate whorls, translucent sensilla hairshaped (Fig. 3D). Maxillary palpus short, basal segment swollen, apical segment usually longer than preceding segment, usually setose, exceptionally asetose (Fig. 3C).

Wing: Costal break indistinct. ApicR1 1.5-2 times the length of Rs. Dorsal setae only on R1 and basal half of R5.

Preabdomen: Terga 2-8 with lateral setae. Terminalia: Fig. 3A-B. Tg9 interrupted and asetose mesally. Ventral emargination of gonocoxites broadly U-shaped, dorsal transverse bridge projecting beyond ventrobasal margin, the latter reinforced. Gonostylus slightly flattened and tapered toward apex. Ejaculatory apodeme much longer than tegmen, apical extension large, funnelshaped. Tegmen slightly tapered toward apex, the latter membranous, blunt. Cerci occasionally projecting beyond tg9.

Female and immature stages. Unknown.

\section{Distribution and phenology:}

All specimens known of $R$. gombakensis are from the type locality, a lowland rainforest in the Selangor Province, West Malaysia. Specimens captured by aspirator were observed swarming over moist, rotten wood, others were taken by sweepnet and Malaise trap elsewhere in the forest.

Etymology: The species name is derived from the type locality, Ulu Gombak. 


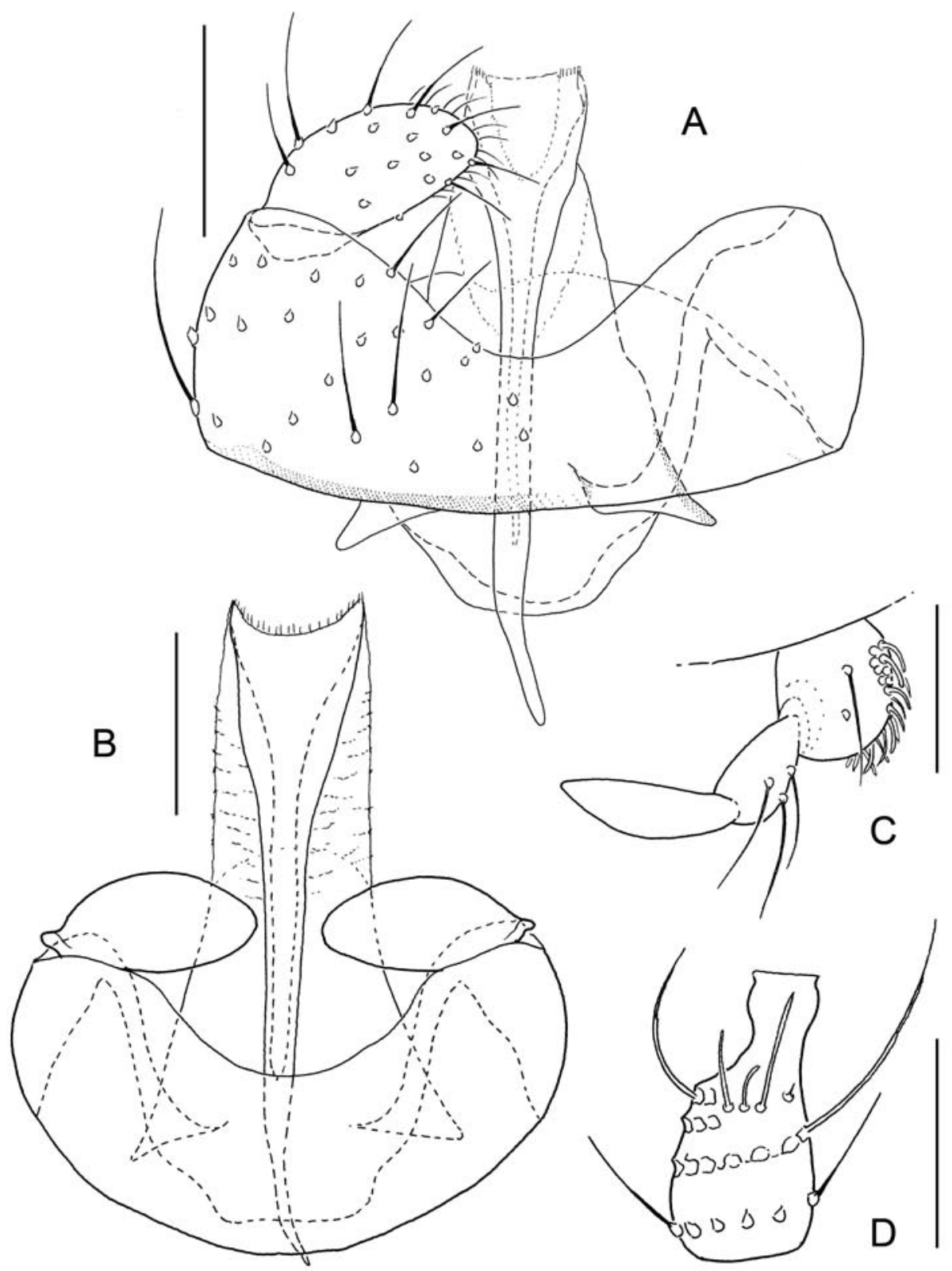

Fig. 3: Ansifera gombakensis sp. n., male. - A: terminalia, ventral view; - B: ditto, ejaculatory apodeme and aedeagus expanded; - C: maxillary palpus, lateral view; - D: fourth antennal flagellomere, lateral view. Length of scale bar $=0.05 \mathrm{~mm}$. 
Types: Holotype: Male, West Malaysia, Selangor, Ulu Gombak, near University of Malaya Field Studies Centre, in primary evergreen rainforest, 250 m, 1 March 1997, by sweepnet, M. JAsCHноF (in NHRS). Paratypes: 3 males, same data as the holotype; 4 males, same data but collected by aspirator (in NHRS).

Other material: 22 males, type locality, various dates between 22 Feb. and 21 March 1997, by Malaise trap, sweepnet \& aspirator, M. JaschHof, H. Hippa \& B. VikLund.

\section{Ansifera asetosa sp. n.}

(Fig. 4A-B)

\section{Diagnosis:}

This is the only species of Ansifera in which the translucent sensilla on the male antennae are leafshaped (Fig. 4A), the wing membrane is devoid of setae, and $\mathrm{CuA} 2$ is practically absent.

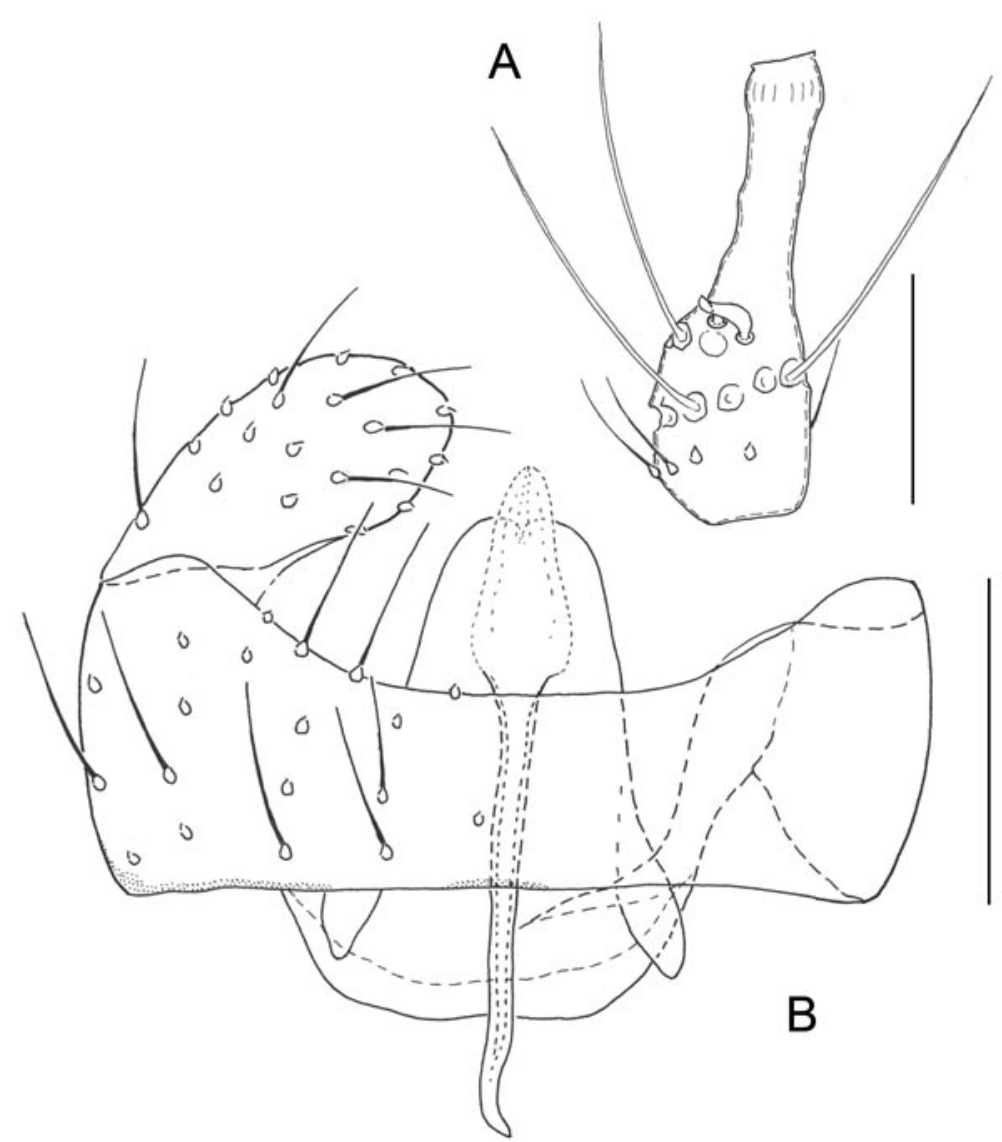

Fig. 4: Ansifera asetosa sp. n., male. - A: fourth antennal flagellomere, lateral view; - B: terminalia, ventral view. Length of scale bar $=0.05 \mathrm{~mm}$. 


\section{Description:}

Male. Body length: 0.9-1.0 mm. Head: Postfrons asetose. Eye bridge 3-4 ommatidia long, shorter laterally than dorsally. Postocular bristles absent. Neck of fourth antennal flagellomere longer than node; node with 1 complete and 1 incomplete crenulate whorl, crenulation poorly developed; translucent sensilla small, irregularly leaf-shaped, arising from 1 to 3 basal pores (Fig. 4A), or such sensilla absent. Maxillary palpus short, basal segment slightly swollen, second segment attached subapically on first, apical segment asetose, slightly longer than preceding segment.

Wing: Costal break missing. ApicR1 1.5 times the length of Rs. CuA2 practically absent. Dorsal setae only on R1. Alar setae absent.

Preabdomen: Terga 2-5 with single lateral setae, terga 6-8 with few lateral and dorsal setae. Terminalia: Fig. 4B. Ventral emargination of gonocoxites shallow, dorsal transverse bridge projecting beyond ventrobasal margin, the latter partly reinforced. Gonostylus comparatively thick, not flattened. Ejaculatory apodeme longer than tegmen, apical extension membranous. Tegmen slightly tapered toward apex, the latter membranous, truncate.

Female and immature stages. Unknown.

\section{Distribution and phenology:}

Ansifera asetosa is only known from the type locality, which is identical to that of the previous species. One of the two specimens was captured over moist, rotten wood, the other specimen was caught elsewhere in forest.

Etymology: The name is Latin, meaning asetose, referring to the bare wing membrane characteristic of this species.

Types: Holotype: Male, West Malaysia, Selangor, Ulu Gombak, near University of Malaya Field Studies Centre, in primary evergreen rainforest, 250 m, 7 March 1997, by aspirator, M. JAsCHHOF (in NHRS). Paratype: 1 male, same locality, 8-21 March 1997, by Malaise trap, H. HippA, M. JaschHof \& B. VIKLUND (in SDEI).

\section{Ansifera longipalpus sp. n.}

(Fig. 5A-D)

\section{Diagnosis:}

In this species regressive morphological characters are least obvious. There is a distinct row of postocular bristles, and both wing veins and setae are well developed. The apical segments of the maxillary palpi are longer than in any other species of Ansifera (Fig. 5C). The pretarsal claws have one relatively strong tooth that points inwards, apart from the ordinary line of fine teeth also present in the congeneric species. The gonostyli are strongly tapered, resulting in an almost subtriangular outline (Fig. 5B), but a variety exists with subcylindrical gonostyli (Fig. 5A).

\section{Description:}

Male. Body length: 1.3-1.5 mm. Head: Postfrons setose. Eye bridge 2-5 ommatidia long, clearly shorter laterally than dorsally. Postocular bristles 5-7. Neck of fourth antennal flagellomere slightly shorter than node; node with 1 complete and 3 incomplete crenulate whorls; translucent sensilla looped, usually with short processes, or simply hair-shaped (Fig. 5D). Maxillary palpus long, basal segment not swollen, apical segment longest of all, usually more than 3 times as long as preceding segment (Fig. 5C). 


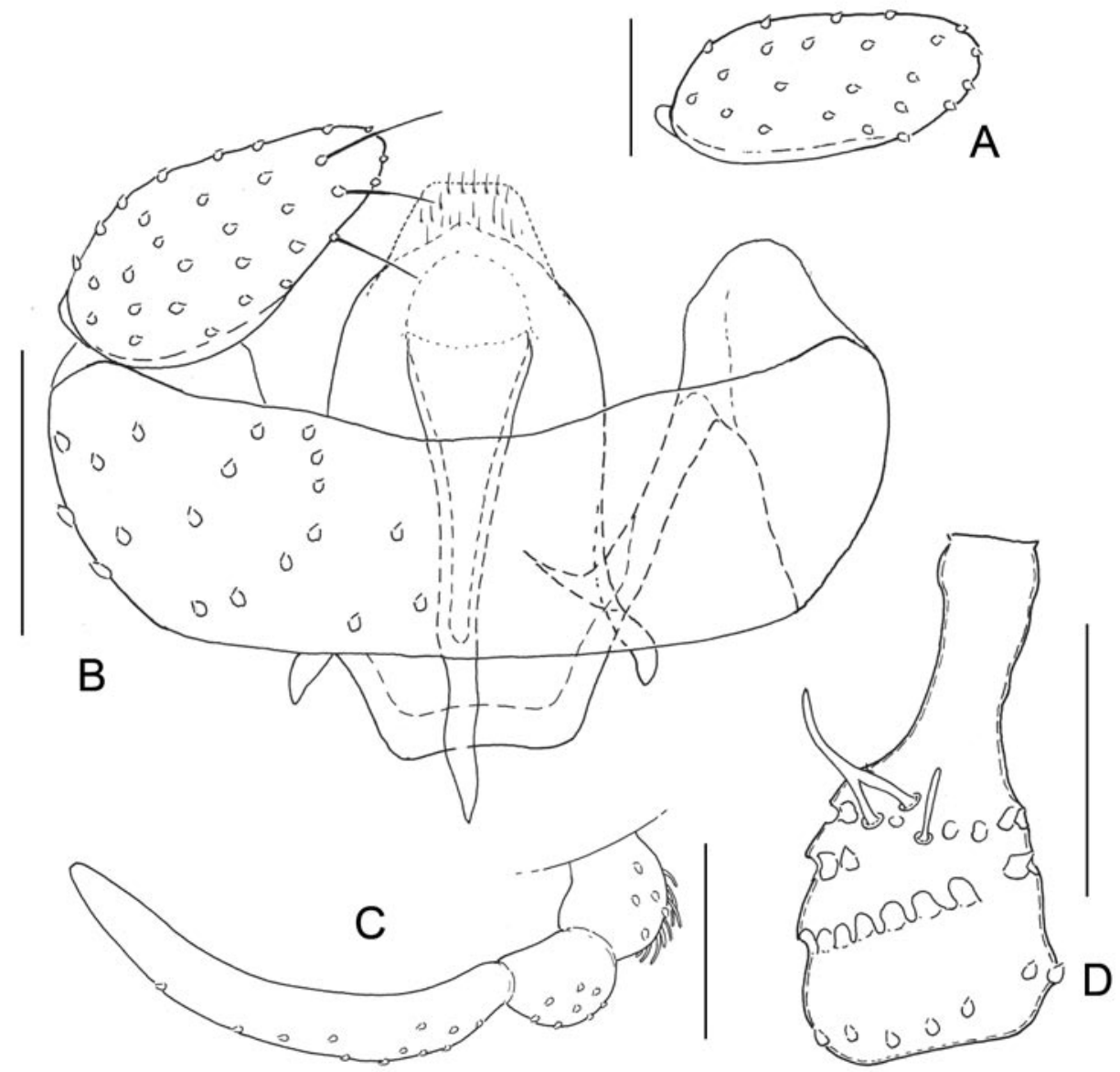

Fig. 5: Ansifera longipalpus sp. n., male. - A: gonostylus, ventral view; - B: terminalia, ventral view; - C: maxillary palpus, lateral view; - D: fourth antennal flagellomere, lateral. Length of scale bar = $0.025 \mathrm{~mm}$ (for A) and $0.05 \mathrm{~mm}$ (for B-D).

Wing: ApicR1 1.5-2 times the length of Rs. Legs: Pretarsal claws with about 5 fine teeth in line and 1 larger tooth directed inwards.

Preabdomen: Terga 2-5 with lateral setae, terga 6-8 with lateral and dorsal setae. Terminalia: Fig. 5B. Gonocoxites with shallow ventral emargination; dorsoapical portions protruding; dorsal transverse bridge subrectangular, projecting beyond ventrobasal margin, the latter not reinforced. Gonostylus strongly tapered toward apex (but see below note on variation), almost subtriangular, slightly flattened. Ejaculatory apodeme longer than tegmen, apical extension funnel-shaped, with fine microtrichia. Tegmen slightly tapered toward apex, the latter of variable outline, weakly membranous.

Female and immature stages: Unknown.

\section{Variation:}

Eighteen male specimens, which were collected together with the types, differ from typical R. longipalpus by their subcylindrical gonostyli with broadly rounded apices (Fig. 5A). Apparently this difference in shape is real, not just the result of different inclination or angle. Even so, I doubt 
that distinct specific status for these specimens is warranted, as all other characters fit the description as given above. Six males collected in a lowland rainforest in the Selangor Province might belong to a species distinct from $R$. longipalpus. In these specimens, the gonocoxites have a deeper ventral emargination and a reinforced ventrobasal margin, and the ejaculatory apodeme is longer and has a more strongly sclerotized apical extension. There are other specimens, from the Malay Peninsula (Pahang and Selangor Provinces, West Malaysia) and Borneo (Sabah), which deviate slightly from $R$. longipalpus in one or more characters, indicating the presence of further, closely similar species. More and better conditioned specimens are needed to identify discriminatory characters and to determine possible infraspecific variation.

\section{Distribution and phenology:}

This species is known from three sites in the Genting Highlands, Pahang Province, West Malaysia. Specimens were captured in primary rainforests at altitudes between 1000 and $1750 \mathrm{~m}$.

Etymology: The name is Latin, referring to the long maxillary palpi typical of this species.

Types: Holotype: Male, West Malaysia, Pahang, Genting Highlands (3.24N:101.47E), in primary evergreen rainforest, 1200-1400 m, 3-22 March 1997, by Malaise trap, H. Hippa, M. JAsCHHof $\&$ B. VikLund (in NHRS). Paratypes: 9 males, same data as the holotype (in NHRS).

Other material: 80 males, same data as the types; 1 male, Genting Highlands, Awana (3.25N:101.46E), $1000 \mathrm{~m}, 10$ March 1997, by aspirator, M. JaschHOF; 1 male, Genting Highlands, Gunung Ulu Kali, 1750 m, 2 March 1997, by sweepnet, M. JAschнof; 1 male, same locality, 5-12 March 1997, by Malaise trap, H. Hippa, M. Jaschнof \& B. VikLund.

\section{Acknowledgements}

Prof H. Yong and Dr R. Hasim, University of Malaya, Kuala Lumpur, are thanked for support of the field work conducted in Malaysia in 1997. The collection of Lestremiinae in Japan in 1998-2000 was made possible through the award of a STA fellowship by the Japan Science and Technology Corporation (award no. 197072) and was assisted by Catrin Jaschhof, Greifswald, Germany. Prof em. Dr Junichi Yukawa, Fukuoka, Japan, and Dr Isamu Okochi, Forestry and Forest Products Research Institute, Tsukuba, Japan, are gratefully acknowledged for their various and invaluable involvement with my research on Japanese Lestremiinae. I thank Dr Keith M. Harris, Ripley, United Kingdom, for reading and commenting on the manuscript and Dr Frank Menzel, Senckenberg Deutsches Entomologisches Institut, Müncheberg, Germany, for a final review.

\section{Literature}

Crook, D. J. \& Mordue, A. J. 1999: Olfactory responses and sensilla morphology of the blackcurrant leaf midge Dasineura tetensi. - Entomologia Experimentalis et Applicata 91: 37-50.

Gagné, R. J. 1981: Cecidomyiidae: 257-292. - In: McAlpine, J. F.; Peterson, B. V.; Shewell, G. E.; Teskey, H. J.; Vockeroth, J. R. \& Wood, D. M. (eds): Manual of Nearctic Diptera. Volume 1. Ottawa: Research Branch Agriculture Canada (Monograph No. 27).

Jaschrof, M. 1998: Revision der "Lestremiinae" (Diptera, Cecidomyiidae) der Holarktis. - Studia dipterologica Supplement 4: 1-552.

Jaschrof, M. 2000: On the Lestremiinae (Diptera: Cecidomyiidae) of Japan. General introduction and part 1: Genus Pseudoperomyia JaschHof \& Hippa, 1999. - Esakia 40: 11-35.

Jaschrof, M. \& Jaschrof, C. 2009: The wood midges (Diptera: Cecidomyiidae: Lestremiinae) of Fennoscandia and Denmark. - Studia dipterologica Supplement 18: 1-333. 
Slifer, E. H. \& Sekhon, S. S. 1971: Circumfila and other sense organs on the antenna of the sorghum midge (Diptera, Cecidomyiidae). - Journal of Morphology 133: 281-302.

Solinas, M. \& Nuzzaci, G. 1987: Antennal sensilla of Mycodiplosis erysipes Ruebs. (Cecidomyiidae, Diptera). - Bolletino dell'Istituto di Entomologia della Università di Bologna 41: 173-194.

ZHANG, J. \& YANG, M. 2008: Scanning electron microscopy of antennae of Aphidoletes aphidimyza (Diptera: Cecidomyiidae). - Zoological Research 29 (1): 108-112.

\section{Author's address:}

Dr. Mathias JaschhoF

Senckenberg Deutsches Entomologisches Institut

Eberswalder Straße 90

15374 Müncheberg

Germany

e-mail: mjaschhof@senckenberg.de

\section{Subject Editor:}

Dr. F. Menzel 